\title{
The effect of ageing with and without non-steroidal anti-inflammatory drugs on gastrointestinal microbiology and immunology
}

\author{
Kirsti Tiihonen ${ }^{1}$, Soile Tynkkynen ${ }^{2}$, Arthur Ouwehand ${ }^{1}$, Terhi Ahlroos ${ }^{2}$ and Nina Rautonen ${ }^{1}$ \\ ${ }^{1}$ Danisco A/S, EnteroMix ${ }^{\mathrm{TM}}$ Research, Sokeritehtaantie 20, Kantvik FIN-02460, Finland \\ ${ }^{2}$ Valio Ltd, R\&D, Helsinki, Finland \\ (Received 21 June 2007 - Revised 31 October 2007 - Accepted 8 November 2007 - First published online 18 February 2008)
}

Elderly individuals are more susceptible to gastrointestinal problems such as constipation than young adults. Furthermore, the common use of nonsteroidal anti-inflammatory drugs (NSAID) among the elderly is known to further increase such gastrointestinal ailments. To describe the specific changes in elderly, intestinal microbes, their metabolites and immune markers were measured from faecal samples obtained from fifty-five elderly individuals (aged 68-88 years), using either NSAID or not, and fourteen young adults (aged 21-39 years). The faecal DM content increased with age but was significantly lower among the elderly NSAID users. The microbial metabolism was especially influenced by NSAID use and/or ageing, although fewer changes were observed in the composition of the microbial community, whilst the level of aerobes was increased in the elderly and the level of Clostridium coccoides-Eubacterium rectale reduced in the elderly NSAID users as compared with young adults. An increase in the concentrations of some branched SCFA and L-lactate but a decrease in some major SCFA concentrations were observed. Evidently, the decreased defecation frequency in the elderly directed colonic fermentation toward an unfavourable microbial metabolism but this was partially offset by the use of NSAID. Irrespective of the use of NSAID, the elderly subjects had significantly lower concentrations of faecal PGE $_{2}$ than the young adults, reflecting possibly a reduced immune response. According to the present study more attention should be paid to the development of dietary products that seek to enhance bowel function, saccharolytic fermentation and immune stimulation in the elderly population.

Intestinal bacteria: Immune responses: Ageing: Non-steroidal anti-inflammatory drugs

Ageing is associated with significant changes in gastrointestinal function. Due to changes in gut physiology, immune system reactivity and diet, elderly individuals are more susceptible to gastrointestinal problems and diseases than young adults. Diseases such as peptic ulcer and gastric cancer, irritable bowel syndrome, diverticulosis and colon cancer are relatively common problems of ageing. Constipation, another common concern in the elderly, often results in increased use of laxatives with ageing ${ }^{(1)}$.

Furthermore, the common use of non-steroidal anti-inflammatory drugs (NSAID) among the elderly may affect their intestinal health. NSAID have analgesic, antipyretic and anti-inflammatory effects. The most common adverse effect caused by NSAID is damage to the mucosa in the gastrointestinal tract ${ }^{(2,3)}$. According to a recent study by Hartikainen et al. ${ }^{(4)}, 70 \%$ of the over-75-year-olds in the city of Kuopio (Finland) take at least one analgesic, of which NSAID are the most commonly used.

During infancy, the intestinal microbiota changes dramatically $^{(5)}$ after which it remains relatively stable during childhood and throughout adult life ${ }^{(6)}$. However, during old age, it has been observed that changes in the composition of the microbiota occur again. Using culture-based methods, it is generally shown that ageing correlates with a decrease in
Bifidobacterium levels ${ }^{(7-9)}$. Using molecular biological methods, such a decrease in total faecal Bifidobacterium counts in the elderly has not been observed. In contrast, levels similar to those normally observed in young adults have been detected ${ }^{(9,10)}$. Other reported changes in the microbiota of seniors are an increase in the numbers of lactobacilli, clostridia and facultative anaerobes ${ }^{(8,11)}$. These changes have, however, received less attention in recent molecular analyses of the intestinal microbiota of the elderly, and appear to be less pronounced than previously considered ${ }^{(9,10)}$.

Weakened immunity in the elderly has been observed by many studies addressing different arms of immune responses both in animal models and, to a lesser degree, in human studies ${ }^{(12)}$. In the present study, faecal IgA, TNF- $\alpha$ and $\mathrm{PGE}_{2}$ were measured. Intestinal $\mathrm{IgA}$ has an important role, not only in neutralising intestinal pathogens but also in the maintenance of gut homeostasis ${ }^{(13)}$. TNF- $\alpha$ mediates the inflammatory responses necessary for successful defence against intracellular infections. Prostaglandins have an essential role in mucosal functions. They inhibit gastric acid secretion, stimulate bicarbonate and mucus secretion and are involved in the regulation of motility and epithelial barrier functions ${ }^{(14)}$. $\mathrm{PGE}_{2}$ has been found to be able to induce proliferative responses in colonocytes as well as in colon cancer

Abbreviation: NSAID, non-steroidal anti-inflammatory drugs.

* Corresponding author: Dr Kirsti Tiihonen, fax +358 92982 203, email kirsti.tiihonen@danisco.com 
cells ${ }^{(15,16)}$. Prostaglandins also perform an important role in the regulation of inflammatory responses ${ }^{(17)}$.

The aim of the present study was to compare gut function, immunological status and the key faecal microbiota components between the elderly subjects, both users and non-users of NSAID, and young adults. This information can aid in the development of products suitable for the different elderly target groups that suffer from gastrointestinal complications.

\section{Materials and methods}

\section{Study subjects}

The study was carried out in two stages. The first part consisted of elderly subjects living in a nursing home and young adults living at a boarding school. The second stage consisted of elderly individuals not living in a nursing home. In total, twenty-six elderly users of NSAID, twentynine elderly non-users of NSAID and fourteen young adults took part in the study in the cities of Kuopio and Helsinki (both in Finland).

The elderly were defined as NSAID users when they used the medication three or more times per week. The NSAID used included indomethacin, ibuprofen, ketoprofen, diclofenac, piroxicam, celecoxib, nimesulid and aspirin. The exclusion criteria were critical illnesses, inflammatory bowel disease, coeliac diseases and major malignancies in the gastrointestinal tract. Subjects using antibiotics during the study or within 2 months before the screening were excluded. The use of probiotic and prebiotic products was not allowed during the study. The inclusion and exclusion criteria were monitored during the run-in period before randomisation. Throughout the sampling both the elderly and the young study subjects followed their habitual diet and most of them used the uniform meal service provided at least once per $d$.

The study protocols were approved by the Research Ethics Committees of the Hospital Districts of Northern Savo and Helsinki-Uusimaa. The purpose of the study was explained to the participants, and written consent to the study was given by all of the subjects. Information on the demographic data, diseases, current medication and use of probiotics and prebiotics were obtained at the beginning of the study.

\section{Faecal samples}

Spot samples of faeces were obtained three times from each subject over 3 consecutive weeks. Subjects were personally instructed to take the faecal samples according to the written protocol. All the equipment and documentation papers were provided to the subjects before sampling. All faecal samples were initially stored at $-20^{\circ} \mathrm{C}$, transferred to the laboratory within $12 \mathrm{~h}$ of defecation and stored at $-70^{\circ} \mathrm{C}$ until analysed.

\section{Physico-chemical analyses}

The concentration of ammonia in the faecal samples was analysed with an enzymic test kit (Boehringer Mannheim/R-Biopharm catalogue no. 11112732 035; R-Biopharm AG, Darmstadt, Germany). The $\mathrm{pH}$ of the faecal samples was measured with a Mettler Toledo InLab 427 (Mettler Toledo
Inc., Columbus, OH, USA) electrode according to protocol 104A:1984 of the International Dairy Federation. For DM determination, about $1 \mathrm{~g}$ of faecal sample was weighed and dried $\left(105^{\circ} \mathrm{C}\right.$ for 16 to $\left.18 \mathrm{~h}\right)$, cooled down in a desiccator to room temperature and reweighed.

The concentrations of acetic, propionic, butyric, valeric, isovaleric, capronic and isocapronic acid were determined by capillary GC (HP-6890; Hewlett Packard, Palo Alto, CA, USA) by adapting the method described by Hoverstad et al. ${ }^{(18)}$ whereby faecal samples were diluted $1: 10$ with $0 \cdot 1 \mathrm{M}$-potassium phosphate buffer ( $\mathrm{pH} 7 \cdot 0$ ), homogenised for $1 \mathrm{~min}$ with a Stomacher blender (Seward, Thetford, Norfolk, UK) and filtered. The filtrate was sonicated for $1 \mathrm{~min}$ at $4^{\circ} \mathrm{C}$ and centrifuged $\left(450 \mathrm{~g} ; 15 \mathrm{~min} ; 4^{\circ} \mathrm{C}\right)$. The samples were stored at $-20^{\circ} \mathrm{C}$. For analysis, a $4 \mathrm{ml}$ sample of faecal suspension was mixed with an internal standard (2-ethyl butyric acid; $5 \mathrm{mg} / 100 \mathrm{~g}$ ), $250 \mu \mathrm{l}$ sulfuric acid pro analysi, $10 \mathrm{ml}$ diethyl ether and approximately $3.5 \mathrm{~g} \mathrm{NaSO}_{4}$ and sonicated for $5 \mathrm{~min}$. The $4 \mathrm{ml}$ sample was then transferred into a heptane-regenerated solid-phase extraction Varian $\mathrm{NH} 2$ cartridge (Varian Inc., Palo Alto, CA, USA). The cartridge was then washed with $5 \mathrm{ml}$ isopropanol-heptane mixture $(1: 3, \mathrm{v} / \mathrm{v})$. The sample was ready for GC after elution with $5 \mathrm{ml}$ of $3 \% \mathrm{HCOOH}$ in diethyl ether.

To analyse the D- and L-lactic acid concentrations, $1 \mathrm{~g}$ of the sample was mixed with $6 \mathrm{ml}$ water. The sample was shaken thoroughly and centrifuged at $7000 \mathrm{rpm}$ for $10 \mathrm{~min}$ and $0.4 \mathrm{ml}$ of the supernatant fraction was transferred into a $1.5 \mathrm{ml}$ microfuge tube. To precipitate protein, $0.4 \mathrm{ml}$ of $0.4 \mathrm{M}-\mathrm{HClO}_{4}$ was added. The sample was kept on ice for $5 \mathrm{~min}$ and centrifuged $(16000 \mathrm{~g} ; 5 \mathrm{~min})$. To neutralise the sample, $0.6 \mathrm{ml}$ of the supernatant fraction was transferred into a new $1.5 \mathrm{ml}$ microfuge tube and $70 \mu \mathrm{l} 2 \mathrm{M}-\mathrm{KOH}$ was added. The sample was kept on ice for $5 \mathrm{~min}$ and centrifuged $(16000 \mathrm{~g} ; 5 \mathrm{~min})$. D- and L-Lactic acid were then analysed enzymically (R-Biopharm E1112821; Darmstadt, Germany) from the supernatant fraction.

\section{Microbial analyses}

The presence and quantity of yeast, anaerobic and aerobic bacteria were analysed by cultivation methods. Faecal samples were thawed in an anaerobic chamber and diluted to a ratio of 1:10 with Wilkins-Chalgren medium (Oxoid Ltd, Basingstoke, Hants, UK) in plastic bags. The mixture was homogenised, a tenfold dilution series was made and the appropriate dilutions were plated on agar. Aerobic bacteria were cultivated for $3 \mathrm{~d}$ and the anaerobic bacteria anaerobically for $5 \mathrm{~d}$ on brain heart infusion agar (Oxoid) at $37^{\circ} \mathrm{C}$. The yeasts were grown on yeast extract-glucose-chloramphenicol agar (YGC agar; International Dairy Federation standard 94B:1990) at $25^{\circ} \mathrm{C}$ for $5 \mathrm{~d}$.

The total bacteria cell counts in faecal samples were determined by flow cytometry (FACSCalibur; Becton Dickinson, Franklin Lakes, NJ, USA) as previously described ${ }^{(19)}$. The bacterial fractions were recovered by suspending faecal samples in a buffer, followed by centrifugation and washing. The cell samples were diluted, fixed and stained with a fluorescent nucleic acid-binding dye (SYTO 24; Molecular Probes, Leiden, The Netherlands). The results are expressed as the quantity of bacteria/g wet faeces. 
DNA was extracted from the recovered bacteria using the method described by Apajalahti et al. ${ }^{(20)}$ whereby bacteria were subjected to five freeze-thaw cycles and subsequently treated with lysozyme and proteinase $\mathrm{K}$. The recovered bacterial DNA was used to quantify the total bifidobacteria, as described by Gueimonde et al. ${ }^{(21)}$. The primers and probe for the detection of sulfate-reducing bacteria were designed using the adenosine-5'-phosphosulfate reductase $\alpha$ gene of Desulfovibrio intestinalis, and for the detection of Clostridium perfringens by using the $\alpha$-toxin gene with PrimerExpress software (Applied Biosystems, Foster City, CA, USA). Quantitative real-time PCR was performed using $1 \mu \mathrm{g}$ of isolated bacterial DNA with primers and probes specific for $C$. perfringens and sulfate-reducing bacteria (Table 1). A $25 \mu$ l amplification reaction consisted of $1 \times$ TaqMan universal master mix (Applied Biosystems) with $300 \mathrm{~nm}$ of both reverse and forward primers, and $200 \mathrm{~nm}$ TaqMan probe (Applied Biosystems). All assays were run on an ABI Prism 7000 Sequence Detection System (Applied Biosystems) using the instrument's default settings for thermal cycling and fluorescence measurements. For standard curves bacterial genomic DNA from C. perfringens (ATCC 13124) and in-house isolated genomic DNA from D. intestinalis (DSM 11275) were applied. Based on the genomic sizes, the weight of one copy of each the $C$. perfringens and D. intestinalis genome was calculated, and the amount of chromosomes in $1 \mathrm{pg}$ was estimated. Standard amplification curves were constructed by using 1, 10, 100 and $1000 \mathrm{pg}$ of bacterial genomic DNA as a template. The results are expressed as the quantity of bacteria/g faeces (fresh weight).

For fluorescence in situ hybridisation (FISH) analysis faecal samples were diluted to the ratio of 1:10 with PBS and homogenised in filter bags for $2 \mathrm{~min}$ with a Stomacher blender. A quantity of $5 \mathrm{ml}$ of the suspension was transferred into a tube containing glass beads (diameter $2 \mathrm{~mm}$ ). The sample was mixed for $30 \mathrm{~s}$ with a test-tube mixer and centrifuged for $2 \mathrm{~min}(250 \mathrm{~g})$ to remove the coarse material. Of the supernatant fraction, $375 \mu \mathrm{l}$ were mixed to a ratio of $1: 4$ with fresh $4 \%$ paraformaldehyde $\left(\mathrm{pH} \mathrm{7.2)}\right.$ and fixed overnight at $4^{\circ} \mathrm{C}$. The fixed bacterial cells were collected $(13000 \mathrm{~g} ; 5 \mathrm{~min})$, washed twice with PBS and re-suspended, first in $150 \mu \mathrm{l}$ PBS, after which an equal volume of $94 \%$ ethanol was added. The suspension was then mixed and stored at $-20^{\circ} \mathrm{C}$ until used. The cell suspension was diluted to a ratio of 1:20 with $\quad 0 \cdot 9 \mathrm{M}-\mathrm{NaCl}-20 \mathrm{~mm}$-tri(hydroxymethyl)-aminomethane$0.1 \%$ SDS ( $\mathrm{pH} 7.2$ ) hybridisation buffer at $50^{\circ} \mathrm{C}$ and a

Table 1. Primers and probes used for the quantitative determination of Clostridium perfringens and Desulfovibrio intestinalis

\begin{tabular}{llr}
\hline Primer name & \multicolumn{1}{c}{ Sequence $5^{\prime} \rightarrow 3^{\prime}$} & Label \\
\hline $\begin{array}{l}\text { D. intestinalis } \\
\text { apsA1F }\end{array}$ & GGC GCT GAA ATG ACC ATG AT & \\
$\begin{array}{l}\text { apsA1R } \\
\text { apsA1Probe }\end{array}$ & GGC CGT AAC CGT CCT TGA A & \\
$\begin{array}{l}\text { C. perfringens } \\
\text { CPTAFW }\end{array}$ & TTT GT CCC GCC CG & 5'FAM \\
CPTARV & CCA TAT CAT CCT & \\
& GTG CAA AAG TCT CAA ACT & \\
CPTAPRO & TAA CAT GTC & \\
\hline
\end{tabular}

fluorescent probe was added to the final concentration of $5 \mathrm{ng} / \mathrm{ml}$. Hybridisation was carried out overnight at $50^{\circ} \mathrm{C}$, then the washing and filtering were performed according to Franks et al. ${ }^{(22)}$. The filters were mounted on a slide with AntiFade reagent (Molecular Probes) and covered with glass. The cells were counted visually with an epifluorescence microscope, examining at least fifteen fields in every sample. The oligonucleotide probes used in the FISH analysis were Cy3-labelled Bfra602 described for the Bacillus fragilis group, and Bdis656 for the B. distasonis group ${ }^{(22)}$, Bif164 for the bifidobacteria ${ }^{(23)}$, Erec482 for the C. coccoidesEubacterium rectale group, Chis 150 for the C. histolyticum group $^{(22)}$, Lab158 for the lactobacilli and enterococci ${ }^{(24)}$ and Fprau0645 for the Faecalibacterium prausnitzii ${ }^{(25)}$.

\section{Immunological analyses}

The concentrations of IgA, TNF- $\alpha$ and $\mathrm{PGE}_{2}$ were measured from the soluble fraction of the faeces. The frozen samples were thawed and extracted with bovine serum albumin as described previously ${ }^{(26)}$ and stored at $-20^{\circ} \mathrm{C}$ before analysis. Concentrations of $\operatorname{IgA}, \mathrm{TNF}-\alpha$ and $\mathrm{PGE}_{2}$ were determined using ELISA according to the respective manufacturer's instructions (E80-102; Bethyl Laboratories, Inc., Montgomery, TX, USA; Biosource Europe S.A., Nivelles, Belgium; Cayman Chemical Company, Ltd, Ann Arbor, MI, USA) and the results were expressed as $\mu \mathrm{g}$ or $\mathrm{pg} / \mathrm{g}$ faeces (fresh weight).

\section{Statistical analysis}

The summary statistics (mean, minimum, maximum) were separately calculated for each group. After performing the initial analysis, the effects of NSAID and age were studied separately by comparing the mean levels of parameters in the various groups using the $t$ test.

The relationships of the correlated variables were studied using principal component analysis. The eigenvalues were calculated, and the percentages of total variation explained by them and the first ten principal components. The statistical analysis was performed using SAS statistical analysis software (version 9; SAS Institute, Cary, NC, USA).

\section{Results}

The baseline characteristics, defecation frequency, quality of faeces and use of laxatives of the participants are presented in Table 2. The mean age of the elderly subjects was 75.6 years (without NSAID) and 77.8 years (with NSAID), compared with the mean age of 28.1 years for the young adults. The self-reported defecation frequency was highest in young adults (1.6 times/d) decreasing in order in the elderly NSAID users (1.1) and non-NSAID users (0.6). Hard faeces were reported by $38 \%$ and laxatives were used by $35 \%$ of the elderly but by none of the young adults. The results of the physico-chemical, microbiological and immunological measurements are presented in Table 3. In general, the most important variables, explaining $77 \%$ of the variation in the present study, were, in descending order, the use of NSAID, age, IgA, PGE 2 , TNF- $\alpha$, DM, pH, ammonia and acetic acid (data not shown). Since NSAID use and age were the variables 
Table 2. Baseline characteristics of the sixty-nine participants of the three groups

\begin{tabular}{lccc}
\hline & $\begin{array}{c}\text { Elderly, no } \\
\text { NSAID }(n \text { 26) }\end{array}$ & $\begin{array}{c}\text { Elderly, with } \\
\text { NSAID }(n \text { 29) }\end{array}$ & $\begin{array}{c}\text { Young } \\
\text { adults }(n \text { 14) }\end{array}$ \\
\hline Men $(n)$ & 10 & 7 & 9 \\
Women $(n)$ & 16 & 22 & 5 \\
Age (years) & & & \\
$\quad$ Mean & $75 \cdot 6$ & $57 \cdot 8$ & $28 \cdot 1$ \\
SD & 4.9 & $70-88$ & 6.5 \\
Range & $68-84$ & $1 \cdot 1$ & $21-39$ \\
Defecation frequency (times/d) & 0.6 & 1.0 & 1.6 \\
$\quad$ Mean & 0.3 & - & 0.7 \\
SD & 1 & 3 & - \\
Quality of faeces & 1 & 16 & 1 \\
$\quad$ Very loose & 10 & 10 & 13 \\
Loose & 11 & - & - \\
$\quad$ Normal & - & 8 & - \\
Hard & 11 & & \\
$\quad$ Very hard & & & \\
Laxative users $(n)$ & & & \\
\hline
\end{tabular}

NSAID, non-steroidal anti-inflammatory drugs.

that explained most of the variation in the study, the effects of NSAID use and age are considered in more detail below.

\section{Effect of use of non-steroidal anti-inflammatory drugs}

The effect of NSAID use was first studied by comparing the elderly NSAID users with the elderly without NSAID, and second with the young subjects, none of whom used NSAID (Table 3; groups 1 v. 2, and groups 2 v. 3).

The mean proportion of faecal DM and the concentrations of isobutyrate, isovaleriate and L-lactate were significantly lower in the elderly with NSAID than in the elderly nonNSAID users $(P<0.001, P<0.01, P<0.01 ; P<0.05$, respectively). The use of NSAID did not have an effect on the measured faecal immune parameters or cause any significant changes in microbiota when compared with the elderly nonNSAID users (Table 3; groups 1 v. 2).

The elderly NSAID users had significantly lower levels of total SCFA $(P<0.05)$, butyric acid $(P<0.05)$, propionic acid $(P<0.01)$, isocapronic acid $(P<0 \cdot 0001), C$. coccoides $-E$. rectale bacteria $(P<0.05)$ and $\mathrm{PGE}_{2}(P<0.01)$ when compared with the young adults (Table 3; groups 2 v. 3). In addition, a trend for lower acetic acid $(P=0.0542)$ and valeric acid $(P=0.0675)$ concentrations and higher numbers of bifidobacteria $(P=0.0657)$ were detected in the elderly NSAID users when compared with the young adults.

\section{The effect of age}

The effect of age was assessed by comparing the elderly nonNSAID users with the young adults (Table 3; groups $1 v .3$ ). The elderly non-NSAID users exhibited higher proportions of faecal DM $(P<0.01)$ and higher numbers of aerobic bacteria than the young adults $(P<0.05)$. Moreover, they had higher concentrations of isobutyric acid $(P<0 \cdot 05)$, isovaleric acid $(P<0.05)$, isocapronic acid $(P<0.0001)$ and L-lactate $(P<0.05)$ than the young adults. Furthermore the elderly non-NSAID users had lower concentrations of propionic acid $(P<0.05)$ and $\mathrm{PGE}_{2}(P<0.05)$ than the young adults.
The combined effects of non-steroidal anti-inflammatory drugs and age

A comparison of the elderly subjects, irrespective of the use of NSAID, with the young adults revealed significantly higher quantities of aerobic bacteria $(P<0.05)$ and higher concentrations of isocapronic acid $(P<0 \cdot 0001)$, but lower concentrations of $\mathrm{PGE}_{2}(P<0.01)$ and propionic acid $(P<0.001)$ in the elderly (Table 3; groups 1 and 2 v. 3). Moreover, there were trends for higher quantities of Lactobacillus/Enterococcus $(P=0.0585)$ and lower amounts of $C$. coccoides $-E$. rectale $(P=0.0676)$ and total bacteria $(P=0.0686)$, lower concentrations of acetic acid $(P=0 \cdot 065)$, butyric acid $(P=0 \cdot 075)$ and the total SCFA $(P=0.0599)$ in the elderly, when compared with the young adults.

\section{Discussion}

Constipation is known to be a common problem among the elderly, as evidenced by the high rate of laxative use ${ }^{(1)}$. In this study population, $35 \%$ of the elderly used laxatives but none of the young adults. Generally the most common defecation frequency is once daily ${ }^{(27)}$. According to this survey the defecation frequency was highest in young adults then decreasing in order in the elderly with NSAID and then without NSAID use. The impaired bowel habit in non-NSAID users supports our finding that non-NSAID users had drier faeces compared with NSAID users. The use of NSAID is known to be associated with gastric damage but not with constipation, which is a typical problem with opioids ${ }^{(28)}$.

The self-reported stool type changed from normal to hard with advancing age: young adults reported a normal stool type but over one-third of elderly reported hard faeces. This is also consistent with the occurrence of increasing DM content of faeces associated with ageing. The faecal DM also correlated negatively to the main SCFA (acetic, propionic and butyric acid; $R-0.391, P=0.001 ; R-0.335, P=0.006$; $R-0.304, P=0.013$, respectively) and the total SCFA ( $R-0.313, P=0.01)$ concentrations, giving support to the hypothesis that accelerated intestinal transit is associated with increased colonic SCFA concentration, as indicated by Lewis \& Heaton ${ }^{(29)}$. The non-NSAID users in particular had altered physical bowel functioning, i.e. significantly higher faecal DM and decreased defecation frequency, which could lead some bacterial groups to decrease or become less active. Such consequences could be caused by a loss of contact by microbes with intestinal mucosa, a lack of energy, or by increased concentrations of toxic substances $^{(30)}$. The NSAID users had more moist faeces than the non-NSAID users, but compared with the young subjects, still lower C. coccoides $-E$. rectale counts and reduced SCFA production.

Clear differences in colonic fermentation were demonstrated: NSAID use and/or age decreased concentrations of SCFA (acetate, propionate, butyrate) but increased concentrations of branched-chain fatty acids and L-lactic acid. Decreased concentrations of the major SCFA may indicate decreased availability of butyrate to the mucosa. Butyrate is the main source of energy in the colonic mucosa ${ }^{(31)}$ and thus any dietary change that can increase its availability in the elderly could have important health implications. Branched fatty acids are themselves not 
Table 3. The comparison between elderly non-steroidal anti-inflammatory drug (NSAID) users and non-users and young adults (per $\mathrm{g}$ or $\mathrm{kg}$ faecal fresh weight (fw)) (Mean, minimum (Min) and maximum (Max) values)

\begin{tabular}{|c|c|c|c|c|c|c|c|c|c|c|c|c|c|c|c|c|}
\hline \multirow[b]{2}{*}{ Variable } & \multicolumn{4}{|c|}{ Elderly non-NSAID users (group 1) } & \multicolumn{4}{|c|}{ Elderly NSAID users (group 2) } & \multicolumn{4}{|c|}{ Young adults (group 3 ) } & \multicolumn{4}{|c|}{$\begin{array}{l}\text { Significance of difference } \\
\text { between groups: } P\end{array}$} \\
\hline & $n$ & Mean & Min & $\operatorname{Max}$ & $n$ & Mean & Min & $\operatorname{Max}$ & $n$ & Mean & Min & $\operatorname{Max}$ & 1 v. 2 & 1 v. 3 & 2 v. 3 & 1 and 2 v. 3 \\
\hline \multicolumn{17}{|l|}{ Physico-chemical } \\
\hline DM (\%) & 25 & 29.42 & 17.94 & $42 \cdot 28$ & 29 & $22 \cdot 50$ & $9 \cdot 34$ & $33 \cdot 10$ & 13 & 24.01 & $18 \cdot 20$ & 30.80 & $* * *$ & $\star \star *$ & & \\
\hline $\mathrm{pH}$ & 26 & 7.09 & 4.69 & 7.90 & 28 & 7.04 & $6 \cdot 17$ & 7.69 & 14 & $7 \cdot 13$ & $6 \cdot 20$ & 8.40 & & & & \\
\hline Ammonia ( $\mathrm{g} / \mathrm{kg} \mathrm{fw})$ & 26 & 0.69 & 0.21 & 1.78 & 28 & 0.79 & 0.24 & 1.68 & 14 & 0.61 & 0.32 & 1.22 & & & & \\
\hline \multicolumn{17}{|l|}{$\begin{array}{l}\text { Microbial metabolites } \\
\text { SCFA (mg/100 g fw) }\end{array}$} \\
\hline Total SCFA & 26 & 488.76 & $116 \cdot 66$ & 1079.00 & 28 & $418 \cdot 77$ & $86 \cdot 24$ & $829 \cdot 70$ & 13 & 599.17 & 365.18 & $1279 \cdot 15$ & & & * & \\
\hline Acetic acid & 26 & 229.74 & 68.97 & 544.00 & 28 & $213 \cdot 68$ & 41.55 & 414.63 & 13 & 290.99 & $172 \cdot 71$ & $672 \cdot 62$ & & & & \\
\hline Butyric acid & 26 & $100 \cdot 03$ & 9.98 & 295.00 & 28 & $85 \cdot 17$ & 0.00 & 265.00 & 13 & 133.35 & 56.22 & 292.09 & & & * & \\
\hline Propionic acid & 26 & 76.06 & 13.73 & 191.00 & 28 & 66.57 & 13.87 & 138.09 & 13 & 114.38 & 61.05 & 251.89 & & * & ** & *** \\
\hline Isovaleric acid $\dagger$ & 26 & 34.80 & 5.65 & $112 \cdot 76$ & 28 & 19.95 & 0.50 & $36 \cdot 00$ & 13 & 22.75 & $9 \cdot 34$ & 34.26 & ** & * & & \\
\hline Isobutyric acid $\dagger$ & 26 & 20.57 & $<1$ & 64.86 & 28 & 11.09 & $<1$ & 22.00 & 13 & $20 \cdot 07$ & $<1$ & 43.65 & ** & * & & \\
\hline Valeric acid $†$ & 26 & 20.44 & $<1$ & 61.37 & 28 & 13.92 & $<1$ & $38 \cdot 70$ & 13 & 13.54 & $<1$ & $22 \cdot 61$ & & & & \\
\hline Capronic acid $\dagger$ & 25 & 7.65 & $<1$ & $42 \cdot 00$ & 28 & 8.61 & $<1$ & 38.00 & 13 & 4.06 & $<1$ & 16.91 & & & & \\
\hline Isocapronic acid $\dagger$ & 26 & 0.29 & $<1$ & 0.50 & 28 & 0.34 & $<1$ & 0.50 & 13 & $<1$ & $<1$ & $<1$ & & $* \star \star \star *$ & 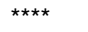 & $\star \star \star \star *$ \\
\hline L-Lactic acid $(\mu \mathrm{mol} / \mathrm{kg} \mathrm{fw}) \ddagger$ & 24 & 1084.00 & $<10$ & 9992.00 & 29 & 161.82 & $<10$ & 1552.66 & 14 & 231.35 & $<10$ & 642.84 & * & * & & \\
\hline D-Lactic acid $(\mu \mathrm{mol} / \mathrm{kg} \mathrm{fw}) \ddagger$ & 24 & 654.76 & $<10$ & 9180.00 & 29 & 376.55 & $<10$ & $1263 \cdot 30$ & 14 & 341.65 & $40 \cdot 11$ & 797.86 & & & & \\
\hline \multicolumn{17}{|l|}{ Microbes $\left(\log _{10}\right.$ cells/g fw) } \\
\hline Total counts & 26 & $11 \cdot 18$ & $10 \cdot 61$ & 11.58 & 27 & $11 \cdot 18$ & 10.50 & 11.77 & 14 & 11.32 & 10.78 & 11.62 & & & & \\
\hline Anaerobes $\left(\log _{10} \mathrm{cfu} / \mathrm{g} \mathrm{fw}\right)$ & 26 & 9.29 & $8 \cdot 15$ & $10 \cdot 11$ & 29 & 9.22 & 8.04 & $10 \cdot 23$ & 14 & $9 \cdot 11$ & $8 \cdot 20$ & 9.83 & & & & \\
\hline Aerobes $\left(\log _{10} \mathrm{cfu} / \mathrm{g} \mathrm{fw}\right)$ & 26 & $7 \cdot 26$ & 5.00 & 8.91 & 29 & $7 \cdot 19$ & 4.67 & $9 \cdot 15$ & 14 & 6.61 & $5 \cdot 30$ & 7.92 & & * & & * \\
\hline Yeasts $\left(\log _{10} \mathrm{cfu} / \mathrm{g} \mathrm{fw}\right) \S$ & 26 & $2 \cdot 12$ & $<2$ & 4.48 & 29 & 2.57 & $<2$ & 6.63 & 14 & 2.46 & $<2$ & 4.72 & & & & \\
\hline Lactobacillus/Enterococcus & 26 & $8 \cdot 28$ & 7.41 & 9.33 & 29 & 8.25 & $7 \cdot 36$ & 9.32 & 14 & 7.94 & 7.06 & $9 \cdot 40$ & & & & \\
\hline $\begin{array}{l}\text { Clostridium coccoides- } \\
\text { Eubacterium rectale }\end{array}$ & 26 & $10 \cdot 19$ & 8.88 & 11.02 & 28 & $10 \cdot 13$ & 9.29 & $10 \cdot 70$ & 14 & $10 \cdot 31$ & 10.01 & 10.71 & & & * & \\
\hline Faecalibacterium prausnitzii & 26 & 8.92 & 5.73 & $10 \cdot 07$ & 29 & $9 \cdot 13$ & 2.85 & 10.05 & 14 & 8.72 & 5.40 & 9.99 & & & & \\
\hline C. histolyticum & 26 & 6.81 & 3.00 & 8.08 & 29 & $7 \cdot 10$ & $5 \cdot 40$ & 9.87 & 14 & 7.09 & $6 \cdot 30$ & $7 \cdot 60$ & & & & \\
\hline Bacteroides & 26 & 9.59 & 8.59 & 10.37 & 29 & 9.72 & 8.23 & 10.45 & 14 & 9.42 & 8.54 & 10.33 & & & & \\
\hline Bifidobacterium & 26 & 9.59 & 5.88 & 10.31 & 27 & 9.83 & 7.67 & 10.44 & 14 & 9.54 & $6 \cdot 10$ & 10.05 & & & & \\
\hline C. perfringens§ & 25 & 6.44 & $<2$ & 7.83 & 27 & $6 \cdot 70$ & $<2$ & 8.05 & 14 & 4.97 & 3.80 & 5.53 & & & & \\
\hline Sulfate reducers§ & 25 & 8.06 & 2.47 & 9.09 & 26 & $7 \cdot 82$ & $<2$ & 9.06 & 10 & $7 \cdot 31$ & 3.63 & 8.25 & & & & \\
\hline \multicolumn{17}{|l|}{ Immunological } \\
\hline $\operatorname{lgA}(\mu \mathrm{g} / \mathrm{g} \mathrm{fw})$ & 26 & 141.53 & 7.58 & 657.78 & 28 & 123.47 & 8.00 & $515 \cdot 00$ & 14 & 153.47 & 21.51 & $585 \cdot 13$ & & & & \\
\hline$P G E_{2}(p g / g f w)$ & 26 & 538.88 & $142 \cdot 00$ & 1111.00 & 28 & 530.46 & 233.00 & 1203.00 & 14 & 1084.50 & $106 \cdot 00$ & 2674.00 & & * & ** & ** \\
\hline TNF- $\alpha(\mathrm{pg} / \mathrm{g} \mathrm{fw})$ & 26 & 1.27 & 0.02 & 5.09 & 28 & 2.56 & 0.02 & $25 \cdot 60$ & 14 & 3.00 & 0.02 & $13 \cdot 28$ & & & & \\
\hline
\end{tabular}

cfu, Colony-forming units.
${ }^{*} P<0.05,{ }^{* \star} P<0.01,{ }^{* \star *} P<0.001,{ }^{* \star * *} P<0.0001$ (pairwise $t$ test).

† Detection limit for isovaleric acid, isobutyric acid, valeric acid, capronic acid and isocapronic acid was $1 \mathrm{mg} / 100 \mathrm{~g} \mathrm{fw}$.

‡Detection limit for L- and D-lactic acid was $10 \mu \mathrm{mol} / \mathrm{kg}$ fw.

$\S$ Detection limit for yeasts was $2 \log _{10}$ cfu/g and for $C$. perfringens and sulfate reducers was $2 \log _{10} \mathrm{cells} / \mathrm{g}$. 
toxic, but are metabolites produced during protein fermentation (for a review, see Blachier et al. ${ }^{(32)}$ ), which are indicating the production of other potentially toxic metabolites, such as indolic and phenolic compounds, which have been linked with long-term adverse health effects such as the development of colon cancer $^{(33)}$.

In the present study, relatively few significant differences in the microbiota of elderly subjects were found when compared with the young. The levels of aerobic bacteria were higher in the elderly non-NSAID users, which is consistent with observations by Woodmansey et al. ${ }^{(34)}$. Although the levels of Lactobacillus/Enterococcus have previously been reported to have increased in the elderly ${ }^{(11,35,36)}$, conflicting results have also been published ${ }^{(9,34)}$. Furthermore, a recent study indicated that age-related differences in Lactobacillus/Enterococcus levels could be country specific ${ }^{(36)}$. There does not seem to be a consistent trend regarding the changes in the levels of these taxonomic groups in the elderly. The present study indicated a trend for increased Lactobacillus/Enterococcus levels in the elderly compared with the young. Although animal studies have indicated increased small-intestinal colonisation with enterococci when treated with the NSAID indometha$\operatorname{cin}^{(37)}$, we did not observe changes in the levels of Lactobacillus/Enterococcus in the NSAID users group. This may relate to methodology which did not distinguish between enterococci and lactobacilli, or the fact that in the present study we analysed faecal rather then small-intestinal microbiota. Consistent with the findings of others ${ }^{(30,35,36)}$ in the combined group of elderly NSAID users and non-users the present study found that the $C$. coccoides $-E$. rectale group, which is among the most numerous groups in adults, had decreased significantly. The commonly reported often-mentioned decrease in faecal bifidobacteria in the elderly ${ }^{(11,38)}$ could not be demonstrated in the present study. A similar difference in results had also been reported earlier by Bartosch et al. ${ }^{(10)}$ and may partly be explained by the differing use of culture-based techniques ${ }^{(11)}$ or molecular-based techniques by Bartosch et al. ${ }^{(10)}$ and the present study.

In the elderly faecal $\mathrm{PGE}_{2}$ levels were significantly decreased to approximately half the levels of those in the young adults irrespective of the use of NSAID. The functions of $\mathrm{PGE}_{2}$ in the large intestine are not fully understood but it has been proposed that ageing in general is associated with the development of a cancer-promoting microenvironment characterised by chronically elevated levels of $\mathrm{PGE}_{2}^{(39)}$. Increased concentrations of $\mathrm{PGE}_{2}$ have been demonstrated previously in vitro in macrophages and in bronchoalveolar lavages obtained from elderly subjects ${ }^{(40,41)}$. In the present study, however, faecal concentrations of $\mathrm{PGE}_{2}$ were clearly decreased in the elderly. This supports previous findings suggesting that ageing decreases prostaglandin concentrations, and thus mucosal protection, in the stomach and duodenum ${ }^{(42)}$.

The volunteers did not exhibit acute-type inflammation in the large intestine, as judged by the low faecal TNF- $\alpha$ concentrations in all test groups, and therefore no indication of increased background inflammation was found ${ }^{(43)}$.

Interestingly, the faecal concentrations of $\operatorname{IgA}$ were similar in all test groups. Although it has previously been suggested that cellular-type immune responses are especially compromised by advanced age, and furthermore that responses are deviated towards humoral immunity, characterised by an increase in serum, bronchoalveolar lavage, and saliva $\operatorname{IgA}$ and IgG concentrations ${ }^{(41,44,45)}$, ageing does not appear to influence the intestinal $\operatorname{IgA}$ concentrations ${ }^{(44)}$. The difference between the intestine and other mucosal sites and serum may be explained by the differing types of regulation of immune responses at the different sites, or by the fact that different immunoglobulin subclasses may change differentially with age ${ }^{(46,47)}$. Furthermore, measurement of specific IgA concentrations after oral vaccination would give a more direct measure of the mucosal responsiveness ${ }^{(48)}$.

In summary, the most significant change in gut content with ageing was the increase in faecal DM and, especially in the elderly NSAID users, a decrease in the activity of microbial metabolism, such as butyrate concentrations. In contrast, an increase in the concentrations of branched fatty acids was detected in both the elderly NSAID users and non-users. Evidently, the decreasing bowel function in the elderly contributes to the changes in colonic fermentation towards an unfavourable putrefactive microbial metabolism. Dietary products that can enhance bowel function and saccharolytic fermentation would be especially beneficial for the elderly. In contrast to systemic and respiratory immune responses, ageing results in a different type of immune profile in the intestine, which is characterised by no change in $\operatorname{IgA}$ concentrations and a clear decrease in $\mathrm{PGE}_{2}$. Therefore, dietary intervention that can normalise the faecal $\mathrm{PGE}_{2}$ concentrations in the elderly will probably reflect an improvement in the protection of the mucosa.

\section{Acknowledgements}

K. T. contributed to the planning of the study, data management, coordination of the manuscript preparation and data interpretation. S. T. contributed partially to the design of the study, microbiological analyses, and manuscript preparation and data interpretation. A. O. contributed to the manuscript preparation and data interpretation. T. A. contributed partially to the microbiological analyses. N. R. coordinated planning of the study, manuscript preparation and data interpretation. The authors thank Markku Saarinen, Brita Mäki, Kirsi Stenström, Jaana Oksanen, Päivi Nurminen, Pia Sigvart-Mattila, Anne-Maria Riihimäki, Tuula Vähäsöyrinki, Juha Laukonmaa, Pirkko Sirviö and Anu Surakka for the various laboratory analyses, Tarja Suomalainen, Essi Sarkkinen, Henna Karvonen and Kajsa Kajander for the practical arrangements, Akra-Numero Research and Consultancy Centre, India for the statistical analysis and John Cowasji for the linguistic form. We especially appreciate the help of the organisers of the sampling in the Pohjois-Savo Vocational Institute in Siilinjärvi and the Harjula Hospital in the District of Northern Savo. We are indebted to the participants of the study for their cooperation and assistance. The study was supported by the National Echnology Agency of Finland (TEKES). There are no conflicts of interest.

\section{References}

1. Harari D, Gurwitz JH, Avorn J, Bohn R \& Minaker KL (1996) Bowel habit in relation to age and gender. Findings from the National Health Interview Survey and clinical implications. Arch Intern Med 156, 315-320. 
2. Bjarnason I, Hayllar J, MacPherson AJ \& Russel AS (1993) Side effects of nonsteroidal anti-inflammatory drugs on the small and large intestine in humans. Gastroenterology 104, $1832-1847$.

3. Laine L, Connors LG, Reicin A, Hawkey CJ, Burgos-Vargas R, Schnitzer TJ, Yu Q \& Bombardier C (2003) Serious lower gastrointestinal clinical events with nonselective NSAID or coxib use. Gastroenterology 124, 288-292.

4. Hartikainen SA, Mäntyselkä PT, Lohivuori-Laako KA \& Sulkava RO (2005) Balancing pain and analgesic treatment in the home-dwelling elderly. Ann Pharmacother 39, 11-16.

5. Favier CF, Vaughan EE, de Vos WM \& Akkermans ADL (2002) Molecular monitoring of succession of bacterial communities in human neonates. Appl Environ Microbiol 68, 219-226.

6. Zoetendal EG, Akkermans ADL \& de Vos WM (1998) Temperature gradient gel electrophoresis analysis of 16S rRNA from human fecal samples reveals stable and host-specific communities of active bacteria. Appl Environ Microbiol 64, $3854-3859$.

7. Mitsuoka T, Hayakawa K \& Kimura N (1974) Die Faekalflora bei Menschen II. Mitteilung: die Zusammensetzung der Bifidobakterienflora der verschiedenen Altersgruppen (The faecal flora of man. II. The composition of bifidobacterium flora of different age groups). Zentralbl Bakteriol (Orig A) 226, 469-478.

8. Mitsuoka T (1990) Bifidobacteria and their role in human health. J Ind Microbiol 6, 263-267.

9. Hopkins MJ, Sarp R \& Macfarlane GT (2001) Age and disease related changes in intestinal bacterial populations assessed by cell culture, 16S rRNA abundance, and community cellular fatty acid profiles. Gut $\mathbf{4 8}, 198-205$.

10. Bartosch S, Woodmansey EJ, Paterson JCM, McMurdo MET \& Macfarlane GT (2005) Microbiological effects of consuming a synbiotic containing Bifidobacterium bifidum, Bifidobacterium lactis, and oligofructose in elderly persons, determined by real-time polymerase chain reaction and counting of viable bacteria. Clin Infect Dis 40, 28-37.

11. Mitsuoka T \& Hayakawa K (1972) Die Faekalflora bei Menschen. I. Mitteilung: die Zusammensetzung der Fecalflora der verschiedenen Altersgruppen (The faecal flora of man. I. The composition of fecal flora of different age groups). Zentralbl Bakteriol (Orig A) 223, 333-342.

12. Gill HS, Darragh AJ \& Cross ML (2001) Optimising immunity and gut function in the elderly. $J$ Nutr Health Aging $\mathbf{5}$, $80-91$.

13. Fagarasan $\mathrm{S} \&$ Honjo $\mathrm{T}$ (2003) Intestinal $\operatorname{Ig} \mathrm{A}$ synthesis: regulation of front-line body defences. Nat Rev Immunol 3, 63-70.

14. Mohajer B \& Ma TY (2000) Eicosanoids and the small intestine. Prostaglandins Other Lipid Mediat 61, 125-143.

15. Dembinski A \& Konturek SJ (1985) Effects of E, F, and I series prostaglandins and analogues on growth of gastroduodenal mucosa and pancreas. Am J Physiol 248, G170-G175.

16. Sheng H, Shao J, Washington MK \& Dubois RN (2001) Prostaglandin E2 increases growth and motility of colorectal carcinoma cells. $J$ Biol Chem 276, 18075-18081.

17. Martin GR \& Wallace JL (2006) Gastrointestinal inflammation: a central component of mucosal defense and repair. Exp Biol Med (Maywood) 231, 130-137.

18. Hoverstad T, Fausa O, Bjorneklett A \& Bohmer T (1984) Shortchain fatty acids in the normal human feces. Scand J Gastroenterol 19, 375-381.

19. Apajalahti JHA, Kettunen H, Kettunen A, Holben WE, Nurminen PH, Rautonen N \& Mutanen M (2002) Culture-independent microbial community analysis reveals that inulin in the diet primarily affects previously unknown bacteria in the mouse cecum. Appl Environ Microbiol 68, 4986-4995.

20. Apajalahti JH, Särkilahti LK, Mäki BR, Heikkinen JP, Nurminen PH \& Holben WE (1998) Effective recovery of bacterial
DNA and percent-guanine-plus-cytosine-based analysis of community structure in the gastrointestinal tract of broiler chickens. Appl Environ Microbiol 64, 4084-4088.

21. Gueimonde M, Tolkko S, Korpimäki T \& Salminen S (2004) New real-time quantitative PCR procedure for quantification of bifidobacteria in human fecal samples. Appl Environ Microbiol 70, 4165-4169.

22. Franks AH, Harmsen HJM, Raangs GC, Jansen GJ, Schut F \& Wellin GW (1998) Variations of bacterial populations in human faeces measured by fluorescent in situ hybridization with groupspecific 16S rRNA-targeted oligonucleotide probes. Appl Environ Microbiol 64, 3336-3345.

23. Langendijk PS, Schut F, Jansen GJ, Raangs GC, Kamphuis GR, Wilkinson MHF \& Welling GW (1995) Quantitative fluorescence in situ hybridization of Bifidobacterium spp. with genus-specific 16S rRNA-targeted probes and its application in fecal samples. Appl Environ Microbiol 61, 3069-3075.

24. Harmsen HJM, Elfferich P, Schut F \& Welling GW (1999) A 16Sr RNA-targeted probe for detection of lactobacilli and enterococci in fecal samples by fluorescent in situ hybridization. Microb Ecol Health Dis 11, 3-12.

25. Suau A, Rochet V, Sghir A, Gramet G, Brewayes S, Sutren M, Rigottier-Gois L \& Dore J (2001) Fusobacterium prausnitzii and related species represent a dominant group within the human fecal flora. System Appl Microbiol 24, 139-145.

26. Peuranen S, Tiihonen K, Apajalahti J, Kettunen A, Saarinen M \& Rautonen N (2004) Combination of polydextrose and lactitol affects microbial ecosystem and immune responses in rat gastrointestinal tract. Br J Nutr 91, 905-914.

27. Heaton KW, Radvan J, Cripps H, Mountford RA, Braddon FE \& Hughes AO (1992) Defecation frequency and timing, and stool form in the general population: a prospective study. Gut 33, 818-824.

28. Pappagallo M (2001) Incidence, prevalence, and management of opioid bowel dysfunction. Am J Surg 182, Suppl. 5A, 11S-18S.

29. Lewis SJ \& Heaton KW (1997) Increasing butyrate concentration in the distal colon by accelerating intestinal transit. Gut 41, 245-251.

30. Tongeren SP, Slaets JP, Harmsen HJ \& Welling GW (2005) Faecal microbiota composition and frailty. Appl Environ Microbiol 71, 6438-6442.

31. Roediger WE (1980) Role of anaerobic bacteria in the metabolic welfare of the colonic mucosa in man. Gut 21, 793-798.

32. Blachier F, Mariotti F, Huneau JF \& Tomé D (2006) Effects of amino acid-derived luminal metabolites on the colonic epithelium and physiopathological consequences. Amino Acids 33, 547-562.

33. Bone E, Tamm A \& Hill MJ (1976) The production of urinary phenols by gut bacteria and their possible role in causation of large bowel cancer. Am J Clin Nutr 29, 1448-1454.

34. Woodmansey EJ, McMurdo MET, Macfarlane GT \& Macfarlane S (2004) Comparison of compositions and metabolic activities of fecal microbiotas in young adults and in antibiotic-treated and non-antibiotic-treated elderly subjects. Appl Environ Microbiol 70, 6113-6122.

35. He T, Harmsen HJM, Raangs GC \& Welling GW (2003) Composition of fecal microbiota of elderly people. Microb Ecol Health Dis 15, 153-159.

36. Mueller S, Saunier K, Hanisch C, et al. (2006) Differences in fecal microbiota in different European study populations in relation to age, gender, and country: a cross-sectional study. Appl Environ Microbiol 72, 1027-1033.

37. Dalby AB, Frank DN, St Amand AL, Bendele AM \& Pace NR (2006) Culture-independent analysis of indomethacin-induced alterations in the rat gastrointestinal microbiota. Appl Environ Microbiol 72, 6707-6715. 
38. Saunier K \& Dore J (2002) Gastrointestinal tract and the elderly: functional foods, gut microflora and healthy ageing. Dig Liver Dis 34, Suppl. 2, 19-24.

39. Schwartsburd PM (2004) Age-promoted creation of a procancer microenvironment by inflammation: pathogenesis of dyscoordinated feed back control. Mech Ageing Dev 125, 581-590.

40. Wu P, Marko M, Claycombe K, Paulson EK \& Meydani SN (2003) Ceramide-induced and age-associated increase in macrophage COX-2 expression is mediated thorugh up-regulation of NK-kB activity. J Biol Chem 278, 10983-10992.

41. Meyer KC (2005) Aging. Proc Am Thorac Soc 2, 433-439.

42. Newton JL (2005) Effect of age-related changes in gastric physiology on tolerability of medication for older people. Drugs Aging 22, 655-661.

43. Lesourd BM \& Meaume S (1994) Cell mediated immunity changes in ageing, relative importance of subpopulation switches and of nutritional factors. Immunol Lett 40, 235-242.
44. Arranz E, O'Mahony S, Barton JR \& Ferguson A (1992) Immunosenescence and mucosal immunity: significant effects of old age on secretory IgA concentrations and intraepithelial lymphocyte counts. Gut 33, 882-886.

45. Lesourd BM, Mazari I \& Ferry M (1998) The role of nutrition in immunity in the aged. Nutr Rev 56, S113-S125.

46. Lottenbach KR, Mink CM, Barenkamp SJ, Anderson SM, Homan SM \& Powers DC (1999) Age-associated differences in immunoglobuin $\mathrm{G} 1$ (IgG1) and IgG2 subclass antibodies to pneumococcal polysaccharides following vaccination. Infect Immun 67, 4935-4938.

47. Powers D (1994) Effect of age on serum immunoglobulin G subclass antibody responses to inactivated influenza virus vaccine. J Med Virol 43, 57-61.

48. Fujihashi K, Koga T \& McGhee JR (2000) Mucosal vaccination and immune resposes in the elderly. Vaccine 18, $1675-1680$ 